\title{
Molecular identification of avian influenza virus subtypes H5N1 and H9N2 in birds from farms and live bird markets and in respiratory patients
}

\author{
Hala M. N. Tolba ${ }^{1}{ }^{\text {, Rasha M. M. Abou Elez }}{ }^{2}$ ， Ibrahim Elsohaby ${ }^{3,4}$, Heba A. Ahmed ${ }^{\text {Corresp. } 2}$ \\ 1 Department of Avian and Rabbit Medicine, Faculty of Veterinary Medicine, Zagazig University, Zagazig, Egypt \\ 2 Department of Zoonoses, Faculty of Veterinary Medicine, Zagazig University, Zagazig, Egypt \\ 3 Department of Animal Medicine, Division of Infectious Diseases, Faculty of Veterinary Medicine, Zagazig University, Zagazig, Egypt \\ 4 Department of Health Management, Atlantic Veterinary College, University of Prince Edward Island, Charlottetown, Prince Edward Island, Canada \\ Corresponding Author: Heba A. Ahmed \\ Email address: heba_ahmed@zu.edu.eg
}

Background. Avian influenza viruses (AIVs) have been endemic in Egypt since 2006, and the co-circulation of high-pathogenic avian influenza H5N1 and low-pathogenic avian influenza H9N2 subtypes in poultry has been reported; therefore, Egypt is considered a hotspot for the generation of new subtypes and genotypes. We aimed to characterize AIVs circulating on commercial farms and in live bird markets (LBMs) during the winters of 2015 and 2016 in the study area and to identify H5N1 and H9N2 viruses in respiratory patients.

Methods. In total, 159 samples were collected from ducks, pigeons and quails on farms ( $\mathrm{n}$ $=59)$ and in LBMs $(n=100)$ and screened by real-time RT-PCR for H5N1 and H9N2 subtypes. Clinical and postmortem examination was carried out on birds from the farms. Positive H5N1 samples were sequenced and analysed for mutations. Tracheal swabs were also collected from 89 respiratory patients admitted to respiratory hospitals in the same study area. Results. Overall, H5N1 was identified in $13.6 \%$ of birds from farms, while it was detected in $17 \%$ of birds in LBMs. Subtype H9N2 was only identified from pigeons on farms $(6.5 \%)$ and LBMs (11.4\%). Sequencing of the haemagglutination gene $(\mathrm{HA})$ in nine representative $\mathrm{H} 5 \mathrm{~N} 1$ isolates revealed a multi-basic amino acid motif at the cleavage site (321-PQGEKRRKKR/GLF-333), which is characteristic of highly pathogenic AIV, in five of our isolates, while the other four isolates showed an amino acid substitution (Q322K) at this cleavage site to make it (321-P K GEKRRKKR/GLF-333). All the isolates belonged to clade 2.2.1.2, and a comparison of HA sequences at the amino acid level showed $98.8-100 \%$ homology among the nine isolates, while they showed $94.1-96.1 \%$ identity with reference strains and the commonly used vaccine strain in Egypt. Out of 89 respiratory patients, 3.4\% were positive for H5N1 and no patients were positive for H9N2. Discussion. Our results indicated the circulation of the endemic $\mathrm{H} 5 \mathrm{~N} 1$ and $\mathrm{H} 9 \mathrm{~N} 2$ viruses among poultry in 2015 and 2016. Birds on farms and in LBMs are reservoirs playing a role in the 
dissemination of the virus and producing a public health risk. The application of proper hygienic measures in farms and LBMs to control the exposure of birds and humans to the source of infection along with continuous monitoring of the circulating viruses will provide information on understanding the evolution of the viruses for vaccine studies. 
1 Molecular identification of avian influenza virus subtypes H5N1 and H9N2 in birds from

2 farms and live bird markets and in respiratory patients

3

4 Hala M. N. Tolba1, Rasha M. M. Abou Elez², Ibrahim Elsohaby ${ }^{3,4}$, Heba A. Ahmed ${ }^{2, *}$

5

$6{ }^{1}$ Department of Avian and Rabbit Medicine, Faculty of Veterinary Medicine, Zagazig University, 7 Zagazig City 44511, Sharkia Governorate, Egypt

$8{ }^{2}$ Department of Zoonoses, Faculty of Veterinary Medicine, Zagazig University, Zagazig City 9 44511, Sharkia Governorate, Egypt

${ }^{3}$ Department of Health Management, Atlantic Veterinary College, University of Prince Edward

Island, Charlottetown, Prince Edward Island, C1A 4P3, Canada

${ }^{4}$ Department of Animal Medicine, Division of Infectious Diseases, Faculty of Veterinary

13 Medicine, Zagazig University, Zagazig City 44511, Sharkia Governorate, Egypt

* Corresponding author: Heba Ahmed

E-mail: heba_ahmed@zu.edu.eg 
23 Abstract

24 Background. Avian influenza viruses (AIVs) have been endemic in Egypt since 2006, and the cocirculation of high-pathogenic avian influenza H5N1 and low-pathogenic avian influenza H9N2 subtypes in poultry has been reported; therefore, Egypt is considered a hotspot for the generation of new subtypes and genotypes. We aimed to characterize AIVs circulating on commercial farms and in live bird markets (LBMs) during the winters of 2015 and 2016 in the study area and to identify $\mathrm{H} 5 \mathrm{~N} 1$ and $\mathrm{H} 9 \mathrm{~N} 2$ viruses in respiratory patients.

Methods. In total, 159 samples were collected from ducks, pigeons and quails on farms $(\mathrm{n}=59)$ and in LBMs $(\mathrm{n}=100)$ and screened by real-time RT-PCR for H5N1 and H9N2 subtypes. Clinical and postmortem examination was carried out on birds from the farms. Positive H5N1 samples were sequenced and analysed for mutations. Tracheal swabs were also collected from 89 respiratory patients admitted to respiratory hospitals in the same study area.

Results. Overall, H5N1 was identified in $13.6 \%$ of birds from farms, while it was detected in $17 \%$ of birds in LBMs. Subtype H9N2 was only identified from pigeons on farms (6.5\%) and LBMs (11.4\%). Sequencing of the haemagglutination gene (HA) in nine representative H5N1 isolates revealed a multi-basic amino acid motif at the cleavage site (321-PQGEKRRKKR/GLF-333), which is characteristic of highly pathogenic AIV, in five of our isolates, while the other four isolates showed an amino acid substitution (Q322K) at this cleavage site to make it (321PKGEKRRKKR/GLF-333). All the isolates belonged to clade 2.2.1.2, and a comparison of HA sequences at the amino acid level showed 98.8-100\% homology among the nine isolates, while they showed $94.1-96.1 \%$ identity with reference strains and the commonly used vaccine strain in

44 Egypt. Out of 89 respiratory patients, 3.4\% were positive for $\mathrm{H} 5 \mathrm{~N} 1$ and no patients were positive 45 for H9N2. 
46 Discussion. Our results indicated the circulation of the endemic H5N1 and H9N2 viruses among

47 poultry in 2015 and 2016. Birds on farms and in LBMs are reservoirs playing a role in the

48 dissemination of the virus and producing a public health risk. The application of proper hygienic

49 measures in farms and LBMs to control the exposure of birds and humans to the source of infection

50 along with continuous monitoring of the circulating viruses will provide information on

51 understanding the evolution of the viruses for vaccine studies.

\section{Introduction}

Influenza A viruses belong to the family Orthomyxoviridae and are categorized into 16 haemagglutinin (HA) subtypes and nine neuraminidase (NA) types in wild and domestic birds (Fouchier et al. 2005). To date, genetic material of influenza viruses of the H17N10 and H18N11 subtypes has been detected in bats (Tong et al. 2012; Tong et al. 2013). In poultry, avian influenza viruses (AIVs) are classified according to the severity of the caused disease as highly pathogenic (HP) and low pathogenic (LP) viruses (Swayne \& Suarez 2000). Infection with LPAIVs is usually benign, including mild respiratory signs with/without a reduction in egg production. However, HPAIVs (especially H5 and H7 subtypes) may cause 100\% mortality (Alexander 2007).

The poultry industry in Egypt consists of two major sectors: commercial (estimated 850 million birds) and backyard (estimated 250 million birds) (Abdelwhab et al. 2010). As a result of insufficient poultry slaughterhouses and the preference for consuming freshly slaughtered birds, the poultry meat trade depends mainly on live bird markets (LBMs) selling live or slaughtered birds for consumers (Abdelwhab et al. 2010). There are two types of LBMs: small retail outlets that depend mainly on commercial poultry and, to a lesser extent, those that sell home-reared birds. The second type of LBM is a large market in each city and village that is held once per week and 
69 includes different vendors for selling birds, vegetables, seeds and other food. Birds of different

70 species (chicken, ducks, geese, quail, pigeons) are usually put together in the same cage

71 (Abdelwhab et al. 2010). The biosecurity standards and veterinary inspections in LBMs are

72 minimal or completely absent. Birds in LBMs originate from different sources, such as farms and

73 home rearing at various localities; which resulted in amplification and dissemination of the virus

74 and increasing the probability of transmission to other birds and humans (Cardona et al. 2009).

75 LBMs are considered critical links for commercial farms, slaughter houses, traders and final

76 consumers (Ibrahim et al. 2007).

77 Since the H5N1 outbreak in Egypt in mid-February 2006, enormous loss in the poultry industry has occurred, and the slaughter campaign overwhelmed the resources of veterinary and public health authorities (Abdelwhab \& Hafez 2011). Despite vaccination and biosecurity measures have been implemented, the disease is still endemic in Egypt and affecting the poultry and public health sectors. Multiple clades of Egyptian A/H5N1 have been reported with at least two distinct genotypes: the 2.2.1.1 clade isolated mainly from vaccinated commercial poultry (and rarely from backyard birds) and the $2.2 .1 / \mathrm{C}$ virus isolated from backyard birds, small-scale commercial poultry and humans (Abdelwhab et al. 2012; Arafa et al. 2012a). Clade 2.2.1.2 has predominated in Egypt since 2011, and the virus has mutations associated with increased binding affinity to human receptors, thus posing a public health risk (Arafa et al. 2016a). concerns arose due to the zoonotic potential of HPAI H5N1 (Naguib et al. 2015). Worldwide, during the 2006 outbreak of HPAI H5N1, 202 persons were infected, and 113 died; most of these victims were in direct contact with infected or dead birds (Wang et al. 2006; WHO 2006). In Egypt, since 2003 till 2017, 359 cases and 120 deaths were reported due to H5N1 (WHO 2017). Most 
92 studies relied on seroprevalence to determine which human cases had the H5N1 subtype (Gomaa

93 et al. 2015). Poultry infected with the H9N2 AIV are usually asymptomatic or show mild clinical

94 signs; however, frequent outbreaks of the virus have been reported in Asia and the Middle East

95 with high mortality (Guo et al. 2000; Naeem et al. 1999), Morocco (EL Houadfi et al., 2016) and

96 Burkina Faso (Zecchin et al., 2017). The co-circulation of HPAI H5N1 and LPAI H9N2 has added

97 an additional risk factor to the poultry industry and humans (Arafa et al. 2012c). Reassortment of

98 these LPAI viruses with HPAI H5N1 could produce novel influenza viruses capable of crossing

99 the interspecies barrier and causing zoonotic transmission and infection in humans (Turner et al.

100 2017). The isolation of H9N2 virus from humans in contact with poultry has been reported

101 indicating its zoonotic potential (Kalthoff et al. 2010; Turner et al. 2017). In Egypt, since 2010,

102 H9N2 has become endemic; furthermore, in 2015, the first human H9N2 case was reported

103 (Naguib et al. 2015). Therefore, this study aimed to characterize AIVs circulating on commercial

104 farms and in LBMs during 2015-2016 in the study area and to identify the H5N1 and H9N2 viruses

105 in respiratory patients.

106

107

\section{Materials and Methods}

\section{Sampling and data collection}

Duck, pigeon and quail samples were collected during the winters of 2015 and 2016 from farms and LBMs in Sharkia Governorate, Egypt. The birds in LBMs were housed in the same cages. The birds from farms were those admitted to the Clinic of Avian and Rabbit Medicine Department, Faculty of Veterinary Medicine, Zagazig University, Egypt. Birds admitted to the clinic were subjected to

113 clinical and postmortem examination. The number of sampled birds from LBMs and farms, 114 respectively, included ducks (45 and 24), pigeons (35 and 31) and quail (20 and 4). None of the birds 
115 from farms or LBMs received AIV vaccines except one duck sample from a farm (collected in 2015).

116 Tracheal swabs from birds in LBMs were pooled (each pool consisted of swabs from 5 birds) and

117 collected in tubes containing 2-3 mL viral transporting medium (VTM), which consists of phosphate-

118 buffered saline (PBS) (Biowhittaker) and PEN-STREP (10000 U penicillin/ml-10000 U

119 streptomycin/ml, Biowhittaker, lonza). From each bird admitted to the clinic, the brain, liver and

120 lungs were pooled and homogenized in $10 \mathrm{~mL}$ sterile PBS. The homogenate was then centrifuged

121 at $2000 \mathrm{rpm}$ for $20 \mathrm{~min}$ at $4^{\circ} \mathrm{C}$. The supernatant was pipetted and transferred to sterile Eppendorf

122 tubes containing $100 \mu \mathrm{L}$ PEN-STREP antibiotic and stored at $-20^{\circ} \mathrm{C}$ until used for real-time RT-

123 PCR and virus isolation.

124 Throat swabs from 89 respiratory patients admitted to respiratory clinics in general hospitals in

125 Sharkia Governorate, Egypt, were collected in VTM tubes. In addition to the sample collection, an

126 epidemiological questionnaire was conducted to collect information about patients, including

127 sociodemographic information (sex, age, occupation, residence, and education level), level of

128 knowledge about AI, attitudes and practices. Informed verbal/written consent for participation in the

129 study was obtained from all the participants, and the study was approved by the Committee of Animal

130 Welfare and Research Ethics (protocol \#12/2015), Faculty of Veterinary Medicine, Zagazig

131 University, Egypt.

132

133 Virus isolation

134 Swabs and tissue homogenates from the examined birds were injected into 9-11-day-old 135 specific pathogen-free embryonated chicken eggs via the allantoic route according to 136 recommendations of the OIE (2012). The allantoic fluid was collected from eggs with dead 
137 embryos after $48 \mathrm{~h}$ and screened by slide haemagglutination test. At least three successive embryo

138 passages were applied for each sample to be negative.

139

Real time RT-PCR Viral RNA from HA allantoic fluids (bird samples) and from human

the manufacturer's guidelines. Primers and probes supplied from Metabion (Germany) targeting of $25 \mu \mathrm{L}$ containing $7 \mu \mathrm{L}$ of RNA template, $12.5 \mu \mathrm{L}$ of $2 \mathrm{x}$ QuantiTect Probe RT-PCR Master Mix

each probe $(30 \mathrm{pmol})$ and $0.25 \mu \mathrm{L}$ of QuantiTect RT Mix. Reverse transcription was performed at $50^{\circ} \mathrm{C}$ for $30 \mathrm{~min}$, followed by primary denaturation at $94^{\circ} \mathrm{C}$ for $15 \mathrm{~min}$, followed by 40 cycles of denaturation at $94^{\circ} \mathrm{C}$ for $15 \mathrm{~s}$, annealing at $54^{\circ} \mathrm{C}$ for $30 \mathrm{~s}$ and extension at $72^{\circ} \mathrm{C}$ for $10 \mathrm{~s}$. The reaction was performed in a STRATAGENE MX3005P real-time RT-PCR machine. Samples that were positive by H9N2 subtype real-time RT-PCR were further confirmed using the same primers in a conventional RT-PCR reaction to assure that the resulting amplification had the correct product size. Extracted RNA was transcribed to cDNA using the RevertAid H Minus First Strand cDNA synthesis kit (Fermentas Inc., Maryland, USA) following the manufacturer's instructions.

\section{Sequence and phylogenetic analysis}

PCR amplification of the H5 gene segment spanning the cleavage site was carried out using the primers and reaction conditions previously described (Njouom et al. 2008). Nine H5N1 isolates from the positive bird samples were selected for sequencing. Amplicons of $311 \mathrm{bp}$ were purified 
160 using a QIAquick PCR Product extraction kit (Qiagen Inc. Valencia CA) according to the 161 manufacturer's guidelines. Sequencing was then carried out using Bigdye Terminator V3.1 cycle 162 sequencing kits (Perkin-Elmer, Foster City, CA) in an Applied Biosystems 3130 genetic analyser 163 (HITACHI, Japan). The HA subtypes were identified by nucleotide BLAST 164 (http://www.ncbi.nlm.nih.gov/BLAST) and submitted to GenBank with accession numbers 165 KX228223, KX228224, KX228225 and KX228226 (winter 2015 samples) and MG725890, 166 MG725891, MG725892, MG725893 and MG725894 (winter 2016 samples). Alignment of the

167 nucleotide sequences with other HA gene sequences available in GenBank was performed by the 168 Clustal W method using the MegAlign module of DNAStar software (Lasergene version 7.2; DNASTAR, Madison, WI, USA). The phylogenetic tree was generated using the neighbourjoining method in MEGA version 7 (www.megasoftware.net). The tree topology was evaluated by 1000 bootstrap analyses.

\section{Statistical analysis}

Statistical analysis was performed using STATA version 15 for Windows (Stata Corp., USA). The prevalence of AIV infection in live birds and human patients was estimated from the ratio of positive to the total number of samples tested. Because of the low number of cases in respiratory patients, the unconditional associations between AIV infection and independent variables (age, gender, occupation, residence, educational level, knowledge about AIV, route of infection, transmission, preventive measures and vaccinations) were assessed by Fisher's exact test. Further, correspondence analysis was used to analyse the relationship between the outcome and categorized independent variables (Greenacre 2017). 
183 Results

184 Clinical and postmortem examination

The farm birds examined in the study were obtained from cases admitted to the Clinic of

Avian and Rabbit Medicine Department, Faculty of Veterinary Medicine, Zagazig University. The ducks showed general signs of illness, such as loss of appetite and decreased feed and water consumption, and specific signs, such as nervous signs (twisting of the neck, trembling and torticollis), respiratory signs (rhinitis, nasal and ocular discharge) and greenish watery diarrhoea.

Pigeons showed nervous signs, including twisting of the neck (Fig. 1A), inability to fly, tremors, incoordination, circling in flight, flying backwards and torticollis. Respiratory signs in some cases and greenish diarrhoea were also observed. None of the quails showed clinical signs except loss of appetite and low egg production.

Postmortem examination of the ducks revealed congestion in the brain with petechial haemorrhage, congestion in the liver and spleen with necrosis and haemorrhage in the pancreas

(Figs. 1B, 1C and 1D). In pigeons, the postmortem lesions showed septicaemia (congested parenchymatous organs) in most organs with congestion in the brain (Figs. 1E and 1F). Quails showed congestion in parenchymatous organs, with congestion in the brain. In female quails, salpingitis and congestion in the uterus were observed.

\section{Virus isolation and haemagglutination}

Inoculation of embryonated chicken eggs with swabs and tissue homogenates from the bird samples revealed mortality and AIV lesions in embryos within 24-48 h in all pigeons and 19 of the duck samples of farm origin. Haemagglutinating viruses were detected in $13(41.9 \%)$ pigeons and $6(25 \%)$ duck samples. With regard to samples from LBMs, inoculated eggs showed lesions 
206 in 15 pigeons, 17 ducks and 4 quail pooled samples. Haemagglutination was observed in 13

207 (37.1\%) pigeons, $14(31.1 \%)$ ducks and one (5\%) quail sample. The HA unit of infective AIV 208 allantoic fluids ranged from $1 / 64$ to $1 / 1024$

209

210

\section{Molecular identification}

211

Positive HA allantoic fluids from pigeon, duck and quail samples were subjected to reverse transcription (RT) real-time RT-PCR for the identification of H5N1 and H9N2 subtypes. The results revealed that the H5N1 subtype was identified in ducks $(16.7 \%)$ and pigeons $(12.9 \%)$ of the farm origin, while H9N2 subtype was only identified in $6.5 \%$ of pigeons (Table 1). All the samples were from non-vaccinated birds except one duck sample (collected in 2015).

Samples from LBMs identified the H5N1 subtype in 20\% of both ducks and pigeons, while

217

218

219

220

221

222

223

224

225

226

227 228

only $5 \%$ of quails were positive by real-time RT-PCR (Table 1). Subtype H9N2 was identified in $11.4 \%$ of pigeons only. Overall, H5N1 subtype was identified in $13.6 \%$ of birds from farms, while it was detected in $17 \%$ of birds from LBMs, which was a nonsignificant difference $(P=0.73)$. The $\mathrm{Ct}$ values from all the examined samples are shown in Supplementary Table (S2).

\section{Sequence and phylogenetic analysis}

$\mathrm{H} 5 \mathrm{~N} 1$ isolates were further confirmed by sequencing and nucleotide BLAST analysis. Sequencing of the HA segment revealed a multi-basic amino acid motif at the cleavage site (321PQGEKRRKKR/GLF-333), which is characteristic of HPAIV, in five of our isolates (Fig. 2). The other four isolates showed an amino acid substitution (Q322K) at this cleavage site to make (321PKGEKRRKKR/GLF-333). In comparison with the reference (parent, classic and variant) strains in Egypt, all the isolates in the current study showed the R325K amino acid substitution, while the 
229 Q322K substitution was found in only four of our isolates compared to the reference and vaccine 230 strains.

231 All the isolates belonged to clade 2.2.1.2 (Fig. 3), and a comparison of HA sequences at the 232 amino acid level showed 98.8-100\% homology among the nine isolates, while they showed 94.1$23396.1 \%$ identity with reference strains and the commonly used vaccine strain 234 (A/chicken/Egypt/Q1995D/2010) in Egypt. A lower similarity rate (90.2-91.6\%) at the amino acid 235 level was detected when compared with the A/duck/Potsdam/1402-6/1986 vaccine strain.

236 Duck isolates in the current study showed 98.8-100\% amino acid homology with the latest 237 circulating duck strains in Sharkia Governorate (A/duck/Egypt/1435CAS/2014) and in Egypt 238 (A/duck/Egypt/2/2015). In contrast, pigeon and quail isolates showed 97.7-100\% amino acid 239 identity with the latest pigeon circulating strain in Sharkia Governorate (A/pigeon/Egypt/Sharkia240 22/2014) and $100 \%$ with the only two quail circulating strains in Egypt 241 (A/quail/Egypt/1171SG/2011) and (A/quail/Egypt/14102TCP/2014).

\section{Human patients}

A total of 89 respiratory patients (age range $10-74$ years), with a higher proportion of females (62.9\%) than males (37.1\%), were involved in this study (Table 2). Approximately 84.3\% of participants had heard about AIV, 56.2\% were rural residents, and only $10.1 \%$ of participants applied AIV preventive measures. Examination of throat swabs from respiratory patients by realtime RT-PCR revealed that 3 out of $89(3.4 \%)$ of the patients were positive for the H5N1 subtype, while none of the samples were positive for H9N2. Fig. 4 illustrates the risk factors associated with AIV infection among the respiratory patients admitted to hospitals. Positive cases were 
252 highlights the close association between AIV cases and hygienic conditions (patients who did not

253 apply any AIV preventive measures). On the other hand, patients without AIV infection (negative

254 cases) were associated with young ( $\leq 19$ years), educated, and hygienic persons who lived in urban 255 areas.

256

\section{Discussion}

The endemic status of H5N1 and H9N2 viruses in Egypt has resulted in outbreaks in poultry and several human cases. The clinical examination of ducks naturally infected with H5N1 in our study revealed nervous signs and diarrhoea, while gross lesions, including congestion and haemorrhages, were observed in all internal organs. These were in accordance with different studies in Egypt (Hafez et al. 2010; Hagag et al. 2015). In Korea, the same observation in naturally infected ducks was reported (Rhyoo et al. 2015; Woo et al. 2011). The susceptibility of pigeons to infection with HPAI H5N1 has been controversial since 2004; however, other studies have documented that pigeons are experimentally susceptible to the virus and could serve as a source of infection for other animals (Mansour et al. 2014; Smietanka et al. 2011; Songserm et al. 2006). Clinical examination of pigeons in the present study revealed nervous signs, greenish diarrhoea and congestion in internal organs. This was in agreement with a recent study that reported the first natural infection of pigeons in Egypt (Mansour et al. 2014). The neurotropic nature of H5N1 in pigeons has been proven experimentally, supporting the observed neurological signs (Klopfleisch et al. 2006). Brain congestion was a predominant lesion in pigeons, and this finding has been reported previously in other studies (Jia et al. 2008; Mansour et al. 2014).

In the current study, the isolation rate of $\mathrm{H} 5 \mathrm{~N} 1$ and $\mathrm{H} 9 \mathrm{~N} 2$ viruses from birds originating

274 from farms was insignificantly lower than the isolation rate from LBMs. Different studies have 
275 compared the isolation rates of AIVs from farms and LBMs; for instance, the detection rate of

276 H5N1 in commercial farm birds $(0.1 \%)$ was significantly lower than that $(11.4 \%)$ of LBMs (El-

277 Zoghby et al. 2013). In contrast, a higher detection rate in commercial farms (6.8\%) versus $3.3 \%$

278 in LBMs was also reported in Egypt (Kayali et al. 2011). The high positivity rate of AIVs in LBMs

279 in our study (17\%) was comparable to $11.5 \%$ (El-Zoghby et al. 2013) and 12.4\% (Abdelwhab et

280 al. 2010) in Egypt, while lower rates of $0.08 \%$ in Nigeria (Joannis et al. 2008), 1.3\% in Thailand

281 (Amonsin et al. 2008) and 3.3\% in Egypt (Kayali et al. 2011) were also reported. In poultry from

282 commercial farms, AIVs were identified in 13.6\% of the samples; in contrast, lower positivity rates

283 were reported in other studies in Egypt (El-Zoghby et al. 2013; Kayali et al. 2011).

284 The detection of HPAI H5N1 in birds from LBMs has an epidemiological impact due to 285 several factors: mixing birds of different origins, species and ages reduces the ability to trace the 286 source of infection; inter- and intra-species transmission of the virus occurs; and importantly, there 287 is increased exposure of vendors, consumers and children to sources of infection (Abdelwhab et 288 al. 2010). Housing and mixing birds in cages for sale in LBMs plays role in the propagation and 289 dissemination of AIVs (Turner et al. 2017).

290 All positive samples from LBMs were from birds with no symptoms, thus indicating the 291 vital role of asymptomatic birds in the persistence and dissemination of the virus (Abdelwhab et 292 al. 2010; Amonsin et al. 2008; Nguyen et al. 2005). Consumers prefer to purchase waterfowl, 293 especially ducks, from LBMs and backyard rearing rather than from commercial farms. The higher 294 detection rate of H5N1 virus from ducks in LBMs indicated the importance of this bird as a silent 295 asymptomatic carrier that plays a role in dissemination and maintenance of the virus for long 296 periods (El-Zoghby et al. 2013; ElMasry et al. 2017; Hassan et al. 2013). 

viruses and could be a source of infection for other animals and subsequently for humans due to their abundance in backyard poultry farms (Mansour et al. 2014; Smietanka et al. 2011; Songserm et al. 2006). In our study, $\mathrm{H} 5 \mathrm{~N} 1$ and $\mathrm{H} 9 \mathrm{~N} 2$ viruses were detected in pigeons from both farms and studies have reported the susceptibility of pigeons to HPAIV and their ability to disseminate the virus (Klopfleisch et al. 2006; Mansour et al. 2014; Smietanka et al. 2011). A few studies have reported the detection of H5N1 virus from naturally infected pigeons in Egypt during 2009 (Elgendy et al. 2016) and 2014 (Mansour et al. 2014; Mansour et al. 2017). The present study reported H5N1 infection in pigeons during 2015 and 2016 in Egypt. Subtype H9N2 was only identified in pigeons from farms (6.5\%) and LBMs (11.4\%); these birds were also co-infected with the H5N1 subtype. This was consistent with other studies in Egypt in different governorates (Kayali et al. 2014; Njabo et al. 2016).

In the present study, none of the quails from farms were positive for AIVs, while only one apparently healthy bird (5\%) from a LBM was positive for H5N1. In accordance, a study conducted in Egypt from 2005-2007 reported the isolation of H5N1 from quails (Mady et al. 2010). Another study reported the confirmation of H5N1 from quails on farms $(0.2 \%)$ and in LBMs (0.8\%) (Arafa et al. 2016b). Quails have been reported to be an important mixing vessel for AIVs due to the expression of receptors for mammalian and avian AIVs on their epithelial cell surfaces (Nguyen et al. 2016; Thontiravong et al. 2012). The infection of quails with HPAI H5N1 has also been reported in different countries worldwide due to the intermingling of quails with other birds in LBMs (Nguyen et al. 2016). None of the quails were positive for H9N2, and this finding was

319 also reported in a recent study (Zahida et al. 2017). In contrast to this finding, another study in 
320 Egypt described the isolation of H9N2 from apparently healthy quail (Arafa et al. 2012b; El-

321 Zoghby et al. 2012).

322 The co-existence of H5N1 and H9N2 subtypes in poultry has been reported, which has

323 caused public health concerns because the endemic H9N2 viruses in Egypt contain elements that

324 may favour avian-to-human transmission (Kandeil et al. 2017; Sun et al. 2011). Moreover, the co-

325 circulation of the two subtypes has resulted in reassortment between the two subtypes, and thus,

326 the reassorted virus has been associated with increased mortality and spread of infection among

327 poultry (Kayali et al. 2014). Therefore, Egypt is considered a hotspot for the generation of new

328 subtypes and genotypes (Abdelwhab \& Abdel-Moneim 2015).

329 The isolates of the current study revealed the presence of a multi-basic amino acid sequence

330 "EKRRKKR/GLF" at the proteolytic cleavage site, which is characteristic of HPAIV. This was

331 consistent with other studies in the same area (Arafa et al. 2016a; ElBakrey et al. 2015; Mansour

332 et al. 2014). This pattern has predominated since 2012, replacing the "ERRRKKR" pattern (Arafa

333 et al. 2016a). All the isolates showed the R325K substitution at the cleavage site, which has been

334 characteristic of 2.2.1.2 clade viruses since 2011 and is consistent with Arafa et al. (2016a). The

335 diversity of the HA gene observed in the current study indicates the active circulation of the virus

336 in the study area. This finding supports the genetic diversity of the H5N1 HA gene in Egypt (Arafa

337 et al. 2016a).

338 Interestingly, Q322K substitution was obvious in four of our isolates compared to the 339 reference and vaccine strains. This is indicative of continuous genetic evolution of the viruses. The

340 higher similarity rate at the amino acid level among our isolates (98.8-100\%) and higher identity

341 between duck (98.8-100\%), pigeon (97.7-100\%) and quail (100\%) when compared with the latest

342 circulating isolates of each indicate the presence of a common ancestor progenitor. Similar 
343 observations were previously reported in the same study area (ElBakrey et al. 2015). Egypt has

344 three major risk factors that contribute to the endemicity of the disease: a high density of domestic

345 waterfowl, high density of the rural human population and abundance of water and irrigation

346 resources (Abdelwhab \& Hafez 2011). The inadequate measures to control AIV in Egypt and the

347 profound genetic drift in the HA gene have resulted in the endemic status of the disease (Kayali et

348 al. 2016). Human cases of H5N1 were mostly caused by infection with viruses in subclade 2.2.1,

349 which frequently circulate in LBMs and backyard poultry (Dudley 2009).

Molecular detection of $\mathrm{H} 5 \mathrm{~N} 1$ and $\mathrm{H} 9 \mathrm{~N} 2$ viruses in 89 respiratory patients revealed that 3.4\% were infected with only the H5N1 subtype. These findings are in agreement with a recent study in

Egypt, where the H5N1 subtype was reported in 5.8\% of respiratory patients (Hussien et al. 2017).

The low detection rate of HPAI H5N1 in human patients was consistent with other findings, thus supporting the previously reported low rate of transmission from birds to humans (Njabo et al. 2016). However, other studies have reported that none of the human participants in contact with infected birds were positive for the virus or antigens (Ghoneim et al. 2014). They attributed this to the need for mutations in the haemagglutination protein in humans for successful transmission from birds (Maines et al. 2011). rural areas, which is a predisposing factor for acquiring $\mathrm{H} 5 \mathrm{~N} 1$ infection; similar findings were previously reported (Hussien et al. 2017). The disease occurs more frequently in rural areas in the Nile Delta due to backyard rearing of birds and more frequent contact with birds sold in LBMs (Njabo et al. 2016). No specific symptoms were observed in the patients with H5N1 infection, which is consistent with other studies (CDC 2016; Hussien et al. 2017). Consequently, diagnosis 365 of avian influenza infection cannot rely on clinical signs. The three positive cases in our study 
366 were adult females ( $>50$ years). Kayali et al. (2011) reported that the case-fatality rate in humans

367 infected with H5N1 was 34\% and was significantly higher in female patients and increased with

368 age. In contrast, the most affected demographic groups are young people and women (Njabo et al.

369 2016). Consistent with our results, recent H5N1 human cases reported exposure to poultry (70\%),

370 and most cases reported fever (98\%), sore throat (94\%) and cough (83\%) (Kayali et al. 2016). The

371 zoonotic potential of the H9N2 subtype and its co-existence with H5N1 have been documented in

372 Egypt through occupational exposure (Gomaa et al. 2015). None of the human cases were positive

373 for H9N2; however, a case was previously reported in South Egypt (OIE 2015). Continuous

374 monitoring and surveillance is essential to prevent this subtype from infecting humans (Njabo et 375 al. 2016).

376

377 Conclusions

378 The findings of this study indicated the circulation of endemic H5N1 and H9N2 viruses 379 among poultry in 2015 and 2016. Birds on farms and in LBMs are reservoirs playing a role in the 380 dissemination of the virus and producing a public health risk. Proper hygienic measures should be 381 applied on farms and in LBMs to control the exposure of birds and humans to the source of 382 infection. Continues surveillance and monitoring of the circulating viruses is important for 383 understanding the evolution of the virus and to better select viruses for vaccine studies to minimize 384 the wide spread of the viral infection.

Acknowledgements 
387 388

392

393

394

395

396

397

398

399

400

401

402

403

404

405

406

407

408

409

410

411

412

413

414

415

416

417

418

419

420

421

422

423

424

425

426

427

The authors are thankful to Dr. Shimaa M. G. Mansour, assistant professor of virology and vet.

Ahmed Magdy, assistant lecturer of zoonoses, Faculty of Veterinary Medicine, Zagazig University; for their valuable advice in analyzing the sequencing data.

\section{References}

Abdelwhab EM, Arafa AS, Stech J, Grund C, Stech O, Graeber-Gerberding M, Beer M, Hassan MK, Aly MM, Harder TC, and Hafez HM. 2012. Diversifying evolution of highly pathogenic H5N1 avian influenza virus in Egypt from 2006 to 2011. Virus Genes 45:1423. $10.1007 / \mathrm{s} 11262-012-0758-1$

Abdelwhab EM, and Hafez HM. 2011. An overview of the epidemic of highly pathogenic H5N1 avian influenza virus in Egypt: epidemiology and control challenges. Epidemiology and Infection 139:647-657. 10.1017/s0950268810003122

Abdelwhab EM, Selim AA, Arafa A, Galal S, Kilany WH, Hassan MK, Aly MM, and Hafez MH. 2010. Circulation of avian influenza H5N1 in live bird markets in Egypt. Avian Diseases 54:911-914. 10.1637/9099-100809-resnote.1

Aguero M, Sanchez A, San Miguel E, Gomez-Tejedor C, and Jimenez-Clavero MA. 2007. A realtime TaqMan RT-PCR method for neuraminidase type 1 (N1) gene detection of H5N1 Eurasian strains of avian influenza virus. Avian Diseases 51:378-381. 10.1637/7642050306r. 1

Alexander DJ. 2007. An overview of the epidemiology of avian influenza. Vaccine 25:5637-5644. 10.1016/j.vaccine.2006.10.051

Amonsin A, Choatrakol C, Lapkuntod J, Tantilertcharoen R, Thanawongnuwech R, Suradhat S, Suwannakarn K, Theamboonlers A, and Poovorawan Y. 2008. Influenza Virus (H5N1) in Live Bird Markets and Food Markets, Thailand. Emerging Infectious Diseases 14:17391742. 10.3201/eid1411.080683

Arafa A, El-Masry I, Kholosy S, Hassan MK, Dauphin G, Lubroth J, and Makonnen YJ. 2016a. Phylodynamics of avian influenza clade 2.2.1 H5N1 viruses in Egypt. Virology Journal 13:49. 10.1186/s12985-016-0477-7

Arafa A, El-Masry I, Khoulosy S, Hassan MK, Soliman M, Fasanmi OG, Fasina FO, Dauphin G, Lubroth J, and Jobre YM. 2016b. Predominance and geo-mapping of avian influenza H5N1 in poultry sectors in Egypt. Geospat Health 11:492. 10.4081/gh.2016.492

Arafa A, Suarez D, Kholosy SG, Hassan MK, Nasef S, Selim A, Dauphin G, Kim M, Yilma J, Swayne D, and Aly MM. 2012a. Evolution of highly pathogenic avian influenza H5N1 
451

452

453

454

455

456

457

458

459

460

461

462

463

464

465

466

467

468

469

470

471

472

473

viruses in Egypt indicating progressive adaptation. Archives of Virology 157:1931-1947. $10.1007 / \mathrm{s} 00705-012-1385-9$

Arafa AS, Hagag N, Erfan A, Mady W, El-Husseiny M, Adel A, and Nasef S. 2012b. Complete genome characterization of avian influenza virus subtype H9N2 from a commercial quail flock in Egypt. Virus Genes 45:283-294. 10.1007/s11262-012-0775-0

Arafa AS, Hagag NM, Yehia N, Zanaty AM, Naguib MM, and Nasef SA. 2012c. Effect of cocirculation of highly pathogenic avian influenza H5N1 subtype with low pathogenic H9N2 subtype on the spread of infections. Avian Diseases 56:849-857. 10.1637/10152040812-Reg.1

Ben Shabat M, Meir R, Haddas R, Lapin E, Shkoda I, Raibstein I, Perk S, and Davidson I. 2010. Development of a real-time TaqMan RT-PCR assay for the detection of H9N2 avian influenza viruses. Journal of Virological Methods 168:72-77. 10.1016/j.jviromet.2010.04.019

Cardona C, Yee K, and Carpenter T. 2009. Are live bird markets reservoirs of avian influenza? Poultry Science 88:856-859. 10.3382/ps.2008-00338

CDC. 2016. Center for disease control and prevention. Influenza signs and symptoms and the role of laboratory diagnostics. http://wwwcdcgov/flu/professionals/diagnosis/labrolesprocedureshtm.

Dudley JP. 2009. Age-specific infection and death rates for human A(H5N1) avian influenza in Egypt. Euro Surveillance 14.

El-Zoghby EF, Aly MM, Nasef SA, Hassan MK, Arafa AS, Selim AA, Kholousy SG, Kilany WH, Safwat M, Abdelwhab EM, and Hafez HM. 2013. Surveillance on A/H5N1 virus in domestic poultry and wild birds in Egypt. Virology Journal 10:203. 10.1186/1743-422x$10-203$

El-Zoghby EF, Arafa AS, Hassan MK, Aly MM, Selim A, Kilany WH, Selim U, Nasef S, Aggor MG, Abdelwhab EM, and Hafez HM. 2012. Isolation of H9N2 avian influenza virus from bobwhite quail (Colinus virginianus) in Egypt. Archives of Virology 157:1167-1172. $10.1007 / \mathrm{s} 00705-012-1269-\mathrm{z}$

El Houadfi M, Fellahi S, Nassik S, Guérin J-L, and Ducatez MF. 2016. First outbreaks and phylogenetic analyses of avian influenza H9N2 viruses isolated from poultry flocks in Morocco. Virology Journal 13:140. 10.1186/s12985-016-0596-1

ElBakrey RM, El Sisi MA, Mansour SM, Ahmed HH, Rajput M, and Eid AA. 2015. Cleavage site stability of Egyptian highly pathogenic avian influenza viruses in backyard chickens during 2009-2011. Journal of Microbiology, Immunology, and Infection Wei Mian Yu Gan Ran Za Zhi 48:28-35. 10.1016/j.jmii.2013.12.002 
474

475

476

477

478

479

480

481

482

483

484

485

486

487

488

489

490

491

492

493

494

495

496

497

498

499

500

501

502

503

504

505

506

507

508

509

510

511

512

513

514

515

516

517

Elgendy EM, Watanabe Y, Daidoji T, Arai Y, Ikuta K, Ibrahim MS, and Nakaya T. 2016. Genetic characterization of highly pathogenic avian influenza $\mathrm{H} 5 \mathrm{~N} 1$ viruses isolated from naturally infected pigeons in Egypt. Virus Genes 52:867-871. 10.1007/s11262-016-1369-z

ElMasry I, Elshiekh H, Abdlenabi A, Saad A, Arafa A, Fasina FO, Lubroth J, and Jobre YM. 2017. Avian Influenza H5N1 Surveillance and its Dynamics in Poultry in Live Bird Markets, Egypt. Transboundary and Emerging Diseases 64:805-814. 10.1111/tbed.12440

Fouchier RA, Munster V, Wallensten A, Bestebroer TM, Herfst S, Smith D, Rimmelzwaan GF, Olsen B, and Osterhaus AD. 2005. Characterization of a novel influenza A virus hemagglutinin subtype (H16) obtained from black-headed gulls. Journal of Virology 79:2814-2822. 10.1128/jvi.79.5.2814-2822.2005

Ghoneim NH, Abdel-Moein KA-A, and Zaher HM. 2014. Epidemiology of avian influenza H5N1 virus in Egypt and its zoonotic potential. Asian Pacific Journal of Tropical Disease 4:S631S634. https://doi.org/10.1016/S2222-1808(14)60693-9

Gomaa MR, Kayed AS, Elabd MA, Zeid DA, Zaki SA, El Rifay AS, Sherif LS, McKenzie PP, Webster RG, Webby RJ, Ali MA, and Kayali G. 2015. Avian influenza A(H5N1) and A(H9N2) seroprevalence and risk factors for infection among Egyptians: a prospective, controlled seroepidemiological study. Journal of Infectious Diseases 211:1399-1407. 10.1093/infdis/jiu529

Greenacre M. 2017. Correspondence Analysis in Practice. Chapmann \& Hall/CRC: Boca Raton.

Guo YJ, Krauss S, Senne DA, Mo IP, Lo KS, Xiong XP, Norwood M, Shortridge KF, Webster RG, and Guan Y. 2000. Characterization of the pathogenicity of members of the newly established H9N2 influenza virus lineages in Asia. Virology 267:279-288. 10.1006/viro.1999.0115

Hafez MH, Arafa A, Abdelwhab EM, Selim A, Khoulosy SG, Hassan MK, and Aly MM. 2010. Avian influenza H5N1 virus infections in vaccinated commercial and backyard poultry in Egypt. Poultry Science 89:1609-1613. 10.3382/ps.2010-00708

Hagag IT, Mansour SMG, Zhang Z, Ali AAH, Ismaiel E-BM, Salama AA, Cardona CJ, Collins J, and Xing Z. 2015. Pathogenicity of Highly Pathogenic Avian Influenza Virus H5N1 in Naturally Infected Poultry in Egypt. PloS One 10:e120061. 10.1371/journal.pone.0120061

Hassan MK, Jobre Y, Arafa A, Abdelwhab EM, Kilany WH, Khoulosy SG, Bakry NR, Baile E, Ali A, Ankers P, and Lubroth J. 2013. Detection of A/H5N1 virus from asymptomatic native ducks in mid-summer in Egypt. Archives of Virology 158:1361-1365. 10.1007/s00705-012-1599-x 
518 Hussien AA, Hassanien AA, Salama S, Ewida R, and Awad M. 2017. Investigation of the 519 emergence of avian and swine influenza among respiratory patients in Assiut University

Ibrahim AA, Albrechtsen L, Upton M, Morgan N, and Rushton J. 2007. Market Impacts of HPAI Outbreaks: A Rapid Appraisal Process, Egypt 2007. Report submitted to FAO 2007. p 33.

Jia B, Shi J, Li Y, Shinya K, Muramoto Y, Zeng X, Tian G, Kawaoka Y, and Chen H. 2008. Pathogenicity of Chinese H5N1 highly pathogenic avian influenza viruses in pigeons. Archives of Virology 153:1821-1826. 10.1007/s00705-008-0193-8

Joannis TM, Meseko CA, Oladokun AT, Ularamu HG, Egbuji AN, Solomon P, Nyam DC, Gado DA, Luka P, Ogedengbe ME, Yakubu MB, Tyem AD, Akinyede O, Shittu AI, Sulaiman LK, Owolodun OA, Olawuyi AK, Obishakin ET, and Fasina FO. 2008. Serologic and virologic surveillance of avian influenza in Nigeria, 2006-7. Eurosurveillance 13:19007. doi:https://doi.org/10.2807/ese.13.42.19007-en

Kalthoff D, Globig A, and Beer M. 2010. (Highly pathogenic) avian influenza as a zoonotic agent. Veterinary Microbiology 140:237-245. 10.1016/j.vetmic.2009.08.022

Kandeil A, El-Shesheny R, Maatouq A, Moatasim Y, Cai Z, McKenzie P, Webby R, Kayali G, and Ali MA. 2017. Novel reassortant H9N2 viruses in pigeons and evidence for antigenic diversity of H9N2 viruses isolated from quails in Egypt. Journal of General Virology 98:548-562. 10.1099/jgv.0.000657

Kayali G, El-Shesheny R, Kutkat MA, Kandeil AM, Mostafa A, Ducatez MF, McKenzie PP, Govorkova EA, Nasraa MH, Webster RG, Webby RJ, and Ali MA. 2011. Continuing threat of influenza (H5N1) virus circulation in Egypt. Emerging Infectious Diseases 17:23062308. 10.3201/eid1712.110683

Kayali G, Kandeil A, El-Shesheny R, Kayed AS, Gomaa MM, Maatouq AM, Shehata MM, Moatasim Y, Bagato O, Cai Z, Rubrum A, Kutkat MA, McKenzie PP, Webster RG, Webby RJ, and Ali MA. 2014. Active surveillance for avian influenza virus, Egypt, 2010-2012. Emerging Infectious Diseases 20:542-551. 10.3201/eid2004.131295

Kayali G, Kandeil A, El-Shesheny R, Kayed AS, Maatouq AM, Cai Z, McKenzie PP, Webby RJ, El Refaey S, Kandeel A, and Ali MA. 2016. Avian Influenza A(H5N1) Virus in Egypt. Emerging Infectious Diseases 22:379-388. 10.3201/eid2203.150593

Klopfleisch R, Werner O, Mundt E, Harder T, and Teifke JP. 2006. Neurotropism of highly pathogenic avian influenza virus A/chicken/Indonesia/2003 (H5N1) in experimentally infected pigeons (Columbia livia f. domestica). Veterinary Pathology 43:463-470. 10.1354/vp.43-4-463

Londt BZ, Nunez A, Banks J, Nili H, Johnson LK, and Alexander DJ. 2008. Pathogenesis of highly pathogenic avian influenza A/turkey/Turkey/1/2005 H5N1 in Pekin ducks (Anas 
564

565

566

567

568

569

570

571

572

573

574

575

576

577

578

579

580

581

582

583

584

585

586

587

588

589

590

591

592

593

594

595

596

597

598

599

600

601

602

603

604

605

606

607

608

609

platyrhynchos) infected experimentally. Avian Pathology 37:619-627. $10.1080 / 03079450802499126$

Mady WH, El-Sanousi AA, Amer HM, El-Sabagh IM, Khafagy AM, and Saber MS. 2010. First year of the Highly Pathogenic Avian Influenza H5N1 outbreak in Egypt: rapid antigenic/molecular diagnosis and virus isolation. International Journal of Virology 6:7381 .

Maines TR, Chen LM, Van Hoeven N, Tumpey TM, Blixt O, Belser JA, Gustin KM, Pearce MB, Pappas C, Stevens J, Cox NJ, Paulson JC, Raman R, Sasisekharan R, Katz JM, and Donis RO. 2011. Effect of receptor binding domain mutations on receptor binding and transmissibility of avian influenza H5N1 viruses. Virology 413:139-147. 10.1016/j.virol.2011.02.015

Mansour SM, ElBakrey RM, Ali H, Knudsen DE, and Eid AA. 2014. Natural infection with highly pathogenic avian influenza virus H5N1 in domestic pigeons (Columba livia) in Egypt. Avian Pathology 43:319-324. 10.1080/03079457.2014.926002

Mansour SMG, Mohamed FF, Eid AAM, Mor SK, and Goyal SM. 2017. Co-circulation of paramyxo- and influenza viruses in pigeons in Egypt. Avian Pathology 46:367-375. $10.1080 / 03079457.2017 .1285391$

Naeem K, Ullah A, Manvell RJ, and Alexander DJ. 1999. Avian influenza A subtype H9N2 in poultry in Pakistan. Veterinary Record 145:560.

Naguib MM, Arafa AS, El-Kady MF, Selim AA, Gunalan V, Maurer-Stroh S, Goller KV, Hassan MK, Beer M, Abdelwhab EM, and Harder TC. 2015. Evolutionary trajectories and diagnostic challenges of potentially zoonotic avian influenza viruses H5N1 and H9N2 cocirculating in Egypt. Infection, Genetics and Evolution 34:278-291. 10.1016/j.meegid.2015.06.004

Nguyen DC, Uyeki TM, Jadhao S, Maines T, Shaw M, Matsuoka Y, Smith C, Rowe T, Lu X, Hall H, Xu X, Balish A, Klimov A, Tumpey TM, Swayne DE, Huynh LP, Nghiem HK, Nguyen HH, Hoang LT, Cox NJ, and Katz JM. 2005. Isolation and characterization of avian influenza viruses, including highly pathogenic $\mathrm{H} 5 \mathrm{~N} 1$, from poultry in live bird markets in Hanoi, Vietnam, in 2001. Journal of Virology 79:4201-4212. 10.1128/jvi.79.7.42014212.2005

Nguyen TH, Than VT, Thanh HD, Hung V-K, Nguyen DT, and Kim W. 2016. Intersubtype Reassortments of H5N1 Highly Pathogenic Avian Influenza Viruses Isolated from Quail. PloS One 11:e0149608. 10.1371/journal.pone.0149608

Njabo KY, Zanontian L, Sheta BN, Samy A, Galal S, Schoenberg FP, and Smith TB. 2016. Living with avian FLU--Persistence of the H5N1 highly pathogenic avian influenza virus in Egypt. Veterinary Microbiology 187:82-92. 10.1016/j.vetmic.2016.03.009 
610

611

612

613

614

615

616

617

618

619

620

621

622

623

624

625

626

627

628

629

630

631

632

633

634

635

636

637

638

639

640

641

642

643

644

645

646

647

648

649

650

651

652

653

654

655

OIE. 2012. Manual of diagnostic tests and vaccines for terrestrial animals (Chapter 2.3.4). http://wwwoieint/en/international-standard-setting/terrestrial-manual/access-online/ accessed on 25 May 2013.

OIE. 2015. World Organization for Animal Health (OIE) manual on animal influenza diagnosis and virological isolation. http://wwwoieint/fileadmin/Home/fr/Health_standards/tahm/20304_AIpdf.

Rhyoo MY, Lee KH, Moon OK, Park WH, Bae YC, Jung JY, Yoon SS, Kim HR, Lee MH, Lee EJ, Ki MR, and Jeong KS. 2015. Analysis of signs and pathology of H5N1-infected ducks from the 2010-2011 Korean highly pathogenic avian influenza outbreak suggests the influence of age and management practices on severity of disease. Avian Pathology 44:175181. 10.1080/03079457.2015.1021295

Slomka MJ, Coward VJ, Banks J, Londt BZ, Brown IH, Voermans J, Koch G, Handberg KJ, Jorgensen PH, Cherbonnel-Pansart M, Jestin V, Cattoli G, Capua I, Ejdersund A, Thoren P, and Czifra G. 2007. Identification of sensitive and specific avian influenza polymerase chain reaction methods through blind ring trials organized in the European Union. Avian Diseases 51:227-234. 10.1637/7674-063006r1.1

Smietanka K, Minta Z, Wyrostek K, Jozwiak M, Olszewska M, Domanska-Blicharz AK, Reichert AM, Pikula A, Habyarimana A, and van den Berg T. 2011. Susceptibility of pigeons to clade 1 and 2.2 high pathogenicity avian influenza H5N1 virus. Avian Diseases 55:106112. 10.1637/9514-090110-ResNote.1

Songserm T, Amonsin A, Jam-on R, Sae-Heng N, Meemak N, Pariyothorn N, Payungporn S, Theamboonlers A, and Poovorawan Y. 2006. Avian Influenza H5N1 in Naturally Infected Domestic Cat. Emerging Infectious Diseases 12:681-683. 10.3201/eid1204.051396

Sun Y, Qin K, Wang J, Pu J, Tang Q, Hu Y, Bi Y, Zhao X, Yang H, Shu Y, and Liu J. 2011. High genetic compatibility and increased pathogenicity of reassortants derived from avian H9N2 and pandemic H1N1/2009 influenza viruses. Proceedings of the National Academy of Sciences of the United States of America 108:4164-4169. 10.1073/pnas.1019109108

Swayne DE, and Suarez DL. 2000. Highly pathogenic avian influenza. Revue Scientifique et Technique 19:463-482.

Thontiravong A, Kitikoon P, Wannaratana S, Tantilertcharoen R, Tuanudom R, Pakpinyo S, Sasipreeyajan J, Oraveerakul K, and Amonsin A. 2012. Quail as a potential mixing vessel for the generation of new reassortant influenza A viruses. Veterinary Microbiology 160:305-313. 10.1016/j.vetmic.2012.05.043

Tong S, Li Y, Rivailler P, Conrardy C, Castillo DA, Chen LM, Recuenco S, Ellison JA, Davis CT, York IA, Turmelle AS, Moran D, Rogers S, Shi M, Tao Y, Weil MR, Tang K, Rowe LA, Sammons S, Xu X, Frace M, Lindblade KA, Cox NJ, Anderson LJ, Rupprecht CE, and Donis RO. 2012. A distinct lineage of influenza A virus from bats. Proceedings of the 
656

657

658

659

660

661

662

663

664

665

666

667

668

669

670

671

672

673

674

675

676

677

678

679

680

681

682

683

684

685

686

687

688

689

690

691

692

693

694
National Academy of Sciences of the United States of America 109:4269-4274. 10.1073/pnas.1116200109

Tong S, Zhu X, Li Y, Shi M, Zhang J, Bourgeois M, Yang H, Chen X, Recuenco S, Gomez J, Chen LM, Johnson A, Tao Y, Dreyfus C, Yu W, McBride R, Carney PJ, Gilbert AT, Chang J, Guo Z, Davis CT, Paulson JC, Stevens J, Rupprecht CE, Holmes EC, Wilson IA, and Donis RO. 2013. New world bats harbor diverse influenza A viruses. PLoS Pathogens 9:e1003657. 10.1371/journal.ppat.1003657

Turner JC, Feeroz MM, Hasan MK, Akhtar S, Walker D, Seiler P, Barman S, Franks J, JonesEngel L, McKenzie P, Krauss S, Webby RJ, Kayali G, and Webster RG. 2017. Insight into live bird markets of Bangladesh: an overview of the dynamics of transmission of H5N1 and H9N2 avian influenza viruses. Emerg Microbes Infect 6:e12. 10.1038/emi.2016.142

Wang M, Di B, Zhou DH, Zheng BJ, Jing H, Lin YP, Liu YF, Wu XW, Qin PZ, Wang YL, Jian LY, Li XZ, Xu JX, Lu EJ, Li TG, and Xu J. 2006. Food markets with live birds as source of avian influenza. Emerging Infectious Diseases 12:1773-1775. 10.3201/eid1211.060675

WHO. 2006. Epidemiology of WHO-confirmed human cases of avian influenza A(H5N1) infection. Weekly Epidemiological Record 81:249-257.

WHO. 2017. Cumulative number of confirmed human cases for avian influenza A (H5N1) reported to WHO, 2003-2016. http://wwwwhoint/influenza/human_animal_ interfacel2016_11_21_tableH5N1pdf?ua=1.

Woo GH, Kim HY, Bae YC, Jean YH, Bak EJ, Kim MJ, Hwang EK, and Joo YS. 2011. Comparative histopathological characteristics of highly pathogenic avian influenza (HPAI) in chickens and domestic ducks in 2008 Korea. Histology and Histopathology 26:167-175. $10.14670 / \mathrm{hh}-26.167$

Zahida F, Muhammad AK, Mansur-ud-Din A, Khushi M, Khalid NK, Amjad K, Zubair A, Abdul A, and Altaf M. 2017. Cross sectional survey of live bird markets and zoo birds for circulating influenza subtypes in Pakistan. Pakistan Veterinary Journal 37:185-189.

Zecchin B, Minoungou G, Fusaro A, Moctar S, Ouedraogo-Kaboré A, Schivo A, Salviato A, Marciano S, and Monne I. 2017. Influenza A(H9N2) Virus, Burkina Faso. Emerging Infectious Diseases 23:2118-2119. 10.3201/eid2312.171294 


\section{Table $\mathbf{1}$ (on next page)}

Proportion of positive samples for H5N1 and H9N2 subtypes determined by RT-PCR. 
1 Table 1. Proportion of positive samples for $\mathrm{H} 5 \mathrm{~N} 1$ and $\mathrm{H} 9 \mathrm{~N} 2$ subtypes determined by RT-PCR.

2

\begin{tabular}{cccccccc}
\hline \multirow{2}{*}{ Birds } & \multicolumn{3}{c}{ Farms } & & \multicolumn{3}{c}{ LBMs } \\
\cline { 2 - 4 } \cline { 7 - 8 } & $\begin{array}{c}\text { Number } \\
\text { examined }\end{array}$ & $\begin{array}{c}\text { H5N1 } \\
\text { subtype }\end{array}$ & $\begin{array}{c}\text { H9N2 } \\
\text { subtype }\end{array}$ & & $\begin{array}{c}\text { Number } \\
\text { examined }\end{array}$ & $\begin{array}{c}\text { H5N1 } \\
\text { subtype }\end{array}$ & $\begin{array}{c}\text { H9N2 } \\
\text { subtype }\end{array}$ \\
\hline Ducks & 24 & $4(16.7 \%)$ & $0(0 \%)$ & & 45 & $9(20 \%)$ & $0(0 \%)$ \\
Pigeons & 31 & $4(12.9 \%)$ & $2(6.5 \%)$ & & 35 & $7(20 \%)$ & $4(11.4 \%)$ \\
Quails & 4 & $0(0 \%)$ & $0(0 \%)$ & & 20 & $1(5 \%)$ & $0(0 \%)$ \\
\hline Total & $\mathbf{5 9}$ & $\mathbf{8 ( 1 3 . 6 \% )}$ & $\mathbf{2 ( 3 . 4 \% )}$ & & $\mathbf{1 0 0}$ & $\mathbf{1 7}(\mathbf{1 7 \%})$ & $\mathbf{4 ( 4 \% )}$ \\
\hline
\end{tabular}

3 
Table 2 (on next page)

Demographic, Knowledge, attitudes and practices data of 89 respiratory patients screened for H5N1 and H9N2 virus infection with real-time RT-PCR. 
1 Table 2. Demographic, Knowledge, attitudes and practices data of 89 respiratory patients

2 screened for H5N1 and H9N2 virus infection with real-time RT-PCR.

\begin{tabular}{|c|c|c|c|}
\hline Variables & $\begin{array}{c}\text { Collected samples, } \\
\text { no. }(\%)\end{array}$ & $\begin{array}{c}\text { Influenza A-positive } \\
\text { samples, no. (\%) } \\
\end{array}$ & $P$-value \\
\hline \multicolumn{4}{|c|}{ I. Demographic characteristics } \\
\hline \multicolumn{4}{|l|}{ Gender } \\
\hline Male & $33(37.1 \%)$ & $0(0 \%)$ & 0.292 \\
\hline Female & $56(62.9 \%)$ & $3(5.4 \%)$ & \\
\hline \multicolumn{4}{|l|}{ Age } \\
\hline$\leq 19$ years & $25(28.1 \%)$ & $0(0 \%)$ & 0.253 \\
\hline $20-49$ years & $25(28.1 \%)$ & $0(0 \%)$ & \\
\hline$\geq 50$ years & $39(43.8 \%)$ & $3(7.7 \%)$ & \\
\hline \multicolumn{4}{|l|}{ Educational level } \\
\hline Illiterate & $30(33.7 \%)$ & $3(10 \%)$ & 0.389 \\
\hline Primary & $9(10.1 \%)$ & $0(0 \%)$ & \\
\hline Secondary & $17(19.1 \%)$ & $0(0 \%)$ & \\
\hline High school & $15(16.8 \%)$ & $0(0 \%)$ & \\
\hline University & $18(20.2 \%)$ & $0(0 \%)$ & \\
\hline \multicolumn{4}{|l|}{ Residence } \\
\hline Rural & $50(56.2 \%)$ & $3(6 \%)$ & 0.173 \\
\hline Urban & $39(43.8 \%)$ & $0(0 \%)$ & \\
\hline \multicolumn{4}{|l|}{ Occupations } \\
\hline Employer & $24(27 \%)$ & $0(0 \%)$ & 0.163 \\
\hline Farmer & $11(12.4 \%)$ & $0(0 \%)$ & \\
\hline Household & $31(34.8 \%)$ & $3(9.7 \%)$ & \\
\hline Student & $23(25.8 \%)$ & $0(0 \%)$ & \\
\hline \multicolumn{4}{|c|}{ II. Knowledge } \\
\hline \multicolumn{4}{|l|}{ Had heard of AIV } \\
\hline Yes & $75(84.3 \%)$ & $3(4 \%)$ & 1.00 \\
\hline No & $14(15.7 \%)$ & $0(0 \%)$ & \\
\hline \multicolumn{4}{|l|}{ AIV is an infectious to human } \\
\hline Yes & $50(56.2 \%)$ & $1(2 \%)$ & 0.264 \\
\hline No & $7(7.9 \%)$ & $1(14.3 \%)$ & \\
\hline Don't know & $32(35.9 \%)$ & $1(3.1 \%)$ & \\
\hline \multicolumn{4}{|l|}{ Information source } \\
\hline Television & $58(65.2 \%)$ & $3(5.2 \%)$ & 1.00 \\
\hline Internet & $17(19.1 \%)$ & $0(0 \%)$ & \\
\hline None & $14(15.7 \%)$ & $0(0 \%)$ & \\
\hline \multicolumn{4}{|l|}{ Knowledge about modes of AIV transmission } \\
\hline Yes & $46(51.7 \%)$ & $0(0 \%)$ & 0.109 \\
\hline No & $43(48.3 \%)$ & $3(7 \%)$ & \\
\hline \multicolumn{4}{|l|}{ Knowledge about AIV symptoms in human } \\
\hline Yes & $46(51.7 \%)$ & $0(0 \%)$ & 0.109 \\
\hline No & $43(48.3 \%)$ & $3(7 \%)$ & \\
\hline \multicolumn{4}{|c|}{ III. Attitudes and Practices } \\
\hline \multicolumn{4}{|l|}{ Direct contact with to poultry } \\
\hline Yes & $56(62.9 \%)$ & $3(5.4 \%)$ & 0.244 \\
\hline No & $33(37.1 \%)$ & $0(5.4 \%)$ & \\
\hline \multicolumn{4}{|c|}{ Use of preventive measures during contact with poultry } \\
\hline Yes & $9(10.1 \%)$ & $0(0 \%)$ & 0.723 \\
\hline No & $80(89.9 \%)$ & $3(3.8 \%)$ & \\
\hline \multicolumn{4}{|l|}{ Healthcare-seeking behaviour } \\
\hline Purchasing cold medicine by myself & $62(69.7 \%)$ & $3(4.8 \%)$ & 0.550 \\
\hline Seeking medical service from hospitals & $27(30.3 \%)$ & $0(0 \%)$ & \\
\hline \multicolumn{4}{|l|}{ Influenza vaccine administration } \\
\hline Yes & $33(37.1 \%)$ & $0(0 \%)$ & 0.244 \\
\hline No & $56(62.9 \%)$ & $3(5.4 \%)$ & \\
\hline Total & 89 & $3(3.4 \%)$ & \\
\hline
\end{tabular}




\section{Figure 1}

Clinical manifestations and PM lesions of birds suspected to be infected with AIVs.

(A) nervous signs (twisting of neck) in 3 months old pigeon, (B) necrosis in pancreas of two months old Balady duck, (C) congestion with petechial hemorrhage in the brain of 1.5 months old Muscovy duck, (D) congestion in spleen of 1.5 months old Muscovy duck, (E) congestion in the brain of 3 months old pigeon with petechial hemorrhage in the inner aspect of the skull, (F) congestion in the liver of 1 year old Balady pigeon.

Photo credit: Hala Tolba.

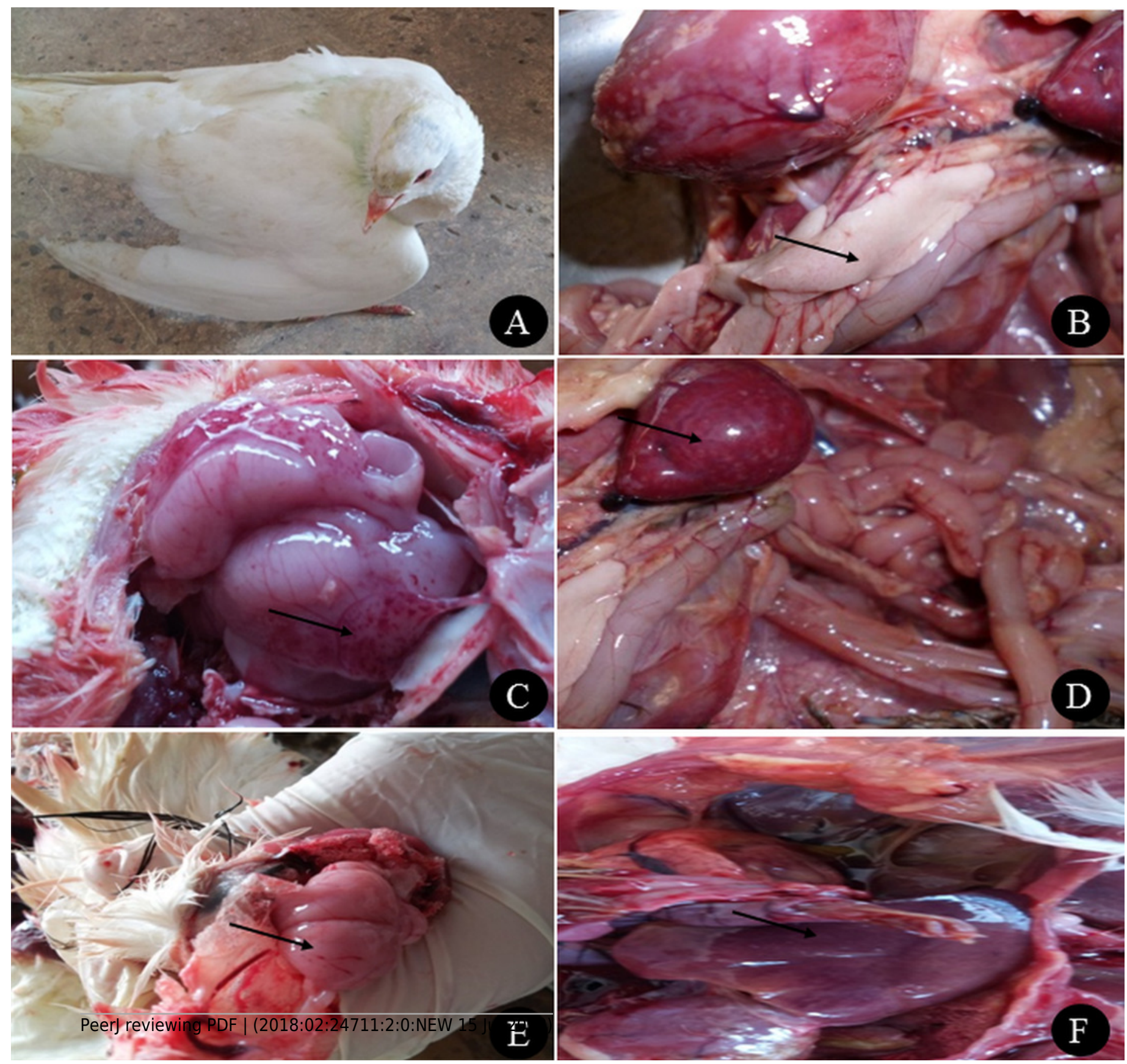




\section{Figure 2}

Deduced amino acid sequences of the HA protein

Deduced amino acid sequences of the HA protein of our isolates (isolates from farms are marked by an asterisk) in comparison to parent (A/chicken/Egypt/06207-NLQP/2006), classic (A/chicken/Egypt/NLQP-0918/2009), variant (A/chicken/Egypt/0879/2008), vaccinal H5N1 (A/chicken/Egypt/Q1995D/2010), H5N2 (A/duck/Potsdam/1402-6/1986) strains and latest duck in Sharkia (A/duck/Egypt/1435CAS/2014), latest duck in Egypt (A/duck/Egypt/2/2015), latest pigeon in Sharkia (A/pigeon/Egypt/Sharkia-22/2014) and latest quail strains in Egypt (A/quail/Egypt/14102TCP/2014 and A/quail/Egypt/1171SG/2011). Dots denote identical amino acids. The H5 influenza numbering was based on the alignment with A/Goose/Guangdong/1/96 (H5N1) minus the 16 amino acids known as HA signal peptide.

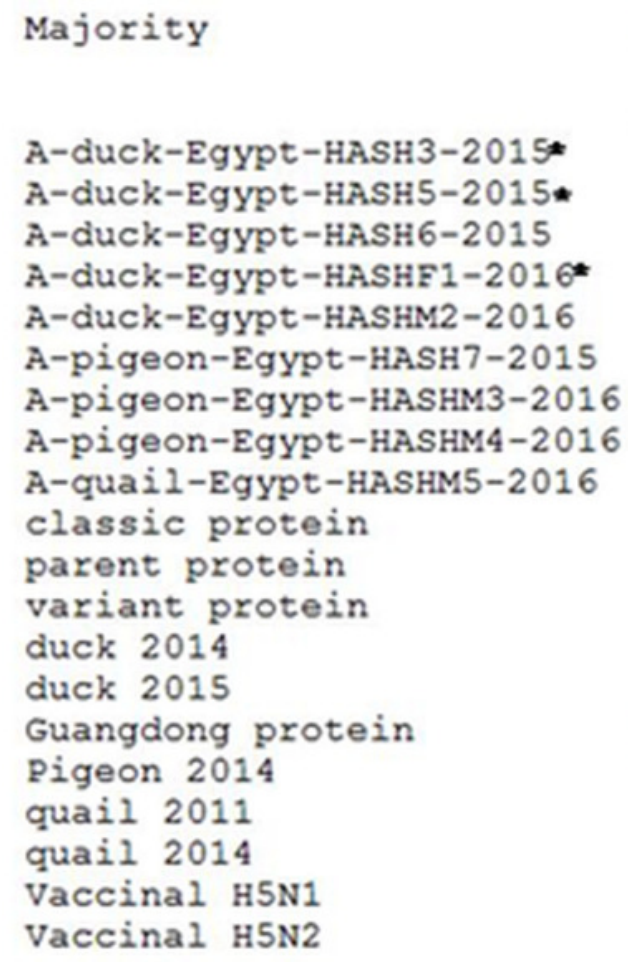
ECPKYVKSNRLVLATGLRNSPQGEKRRKKRGLFGAIAGFIEGGWQGMVDGW

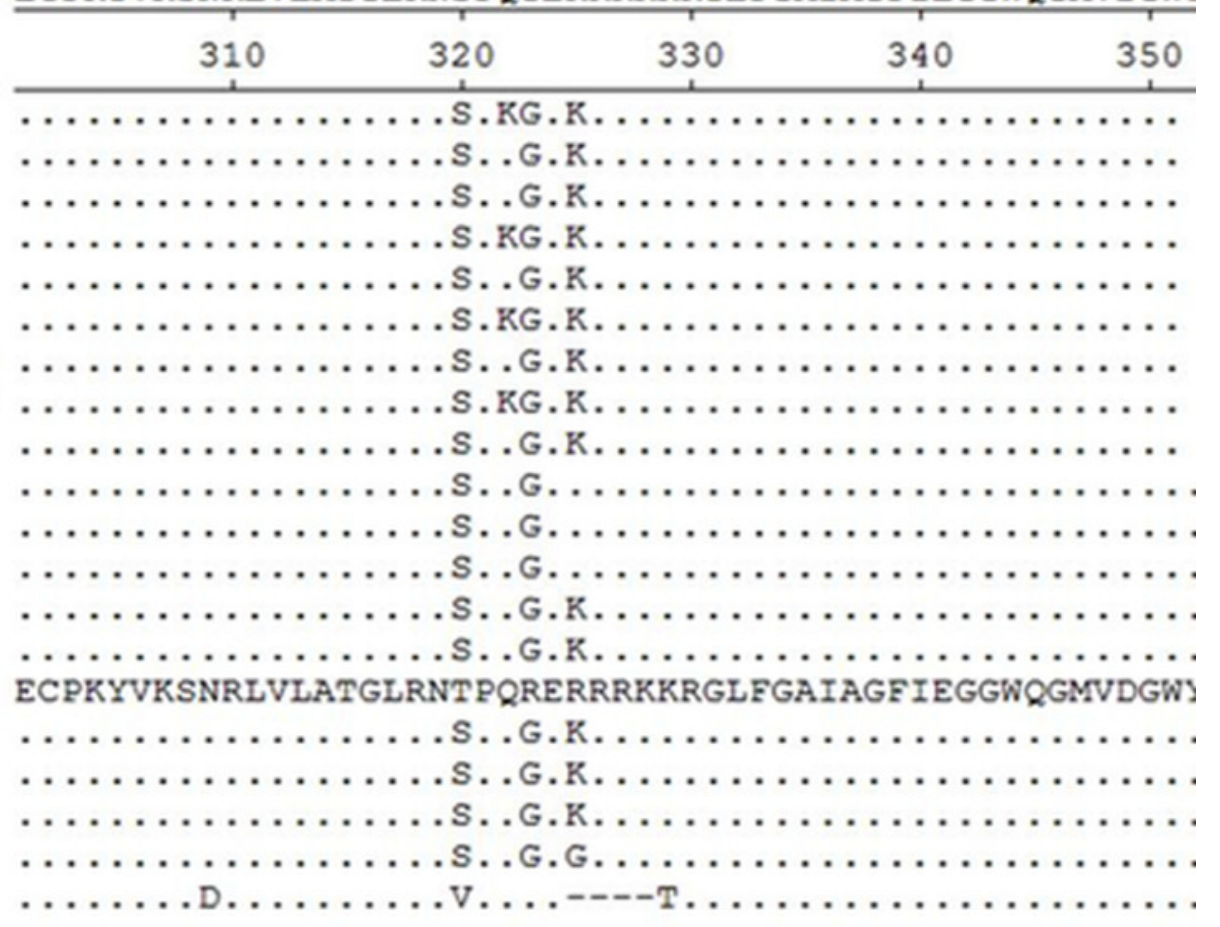




\section{Figure 3}

Phylogenetic analysis of HA gene nucleotide sequences of avian influenza virus (AIV) isolated from ducks, pigeons and quail, Sharkia, Egypt and other sequences available in GenBank.

The strains isolated in winter 2015 are marked by solid circles, while those of winter 2016 are marked with solid squares and vaccinal strains are marked with solid triangles. The tree was constructed via multiple alignments of 300-bp nucleotide sequence of HA gene using the neighbor-joining method and the Kimura-2-parameter model in MEGA7. The tree topology was evaluated by 1000 bootstrap analyses. 


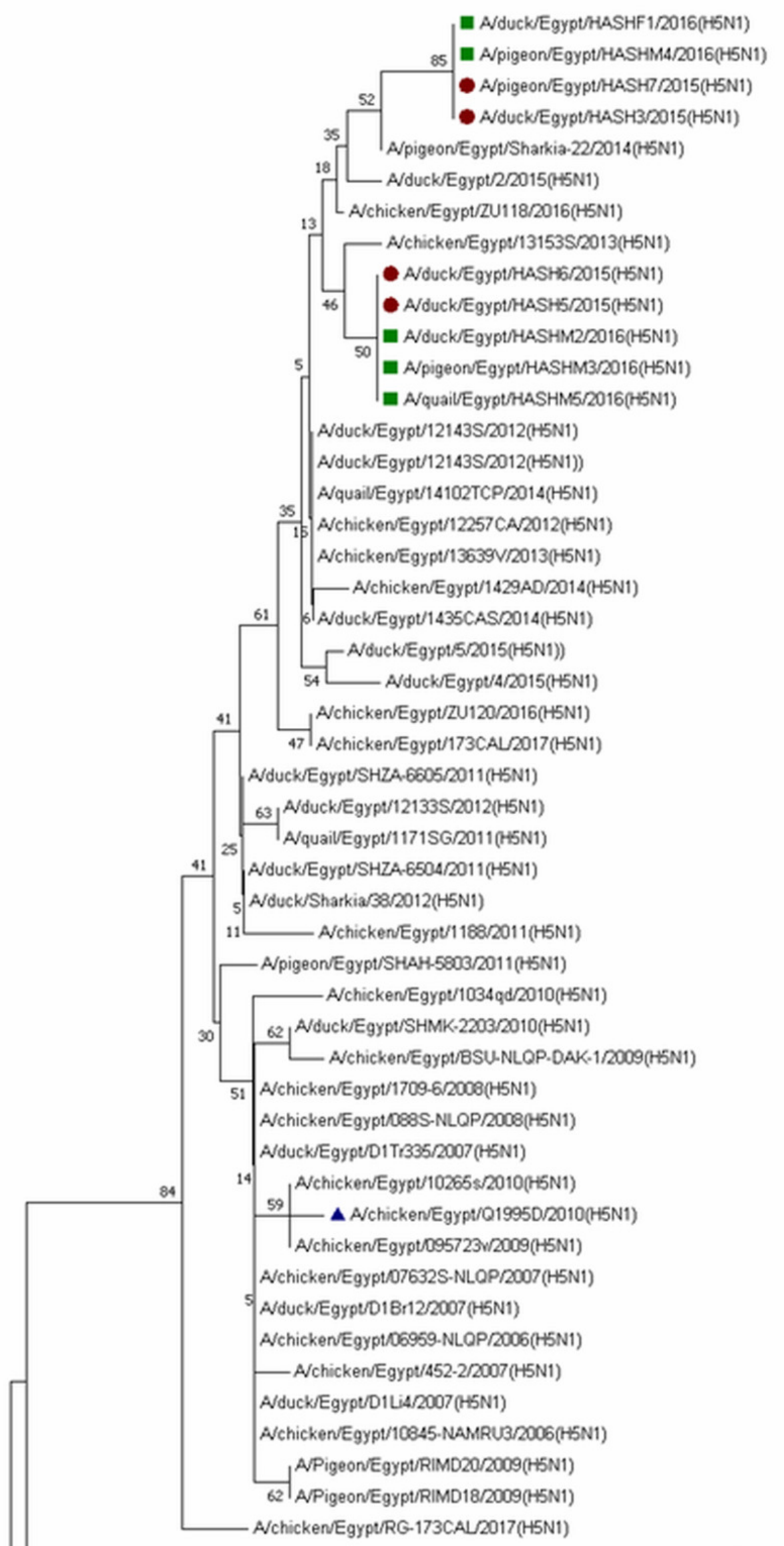




\section{Figure 4}

Multiple correspondence analysis of risk factors associated with the avian influenza virus (AIV) infections in respiratory patients admitted to the general hospitals in Sharkia Governates.

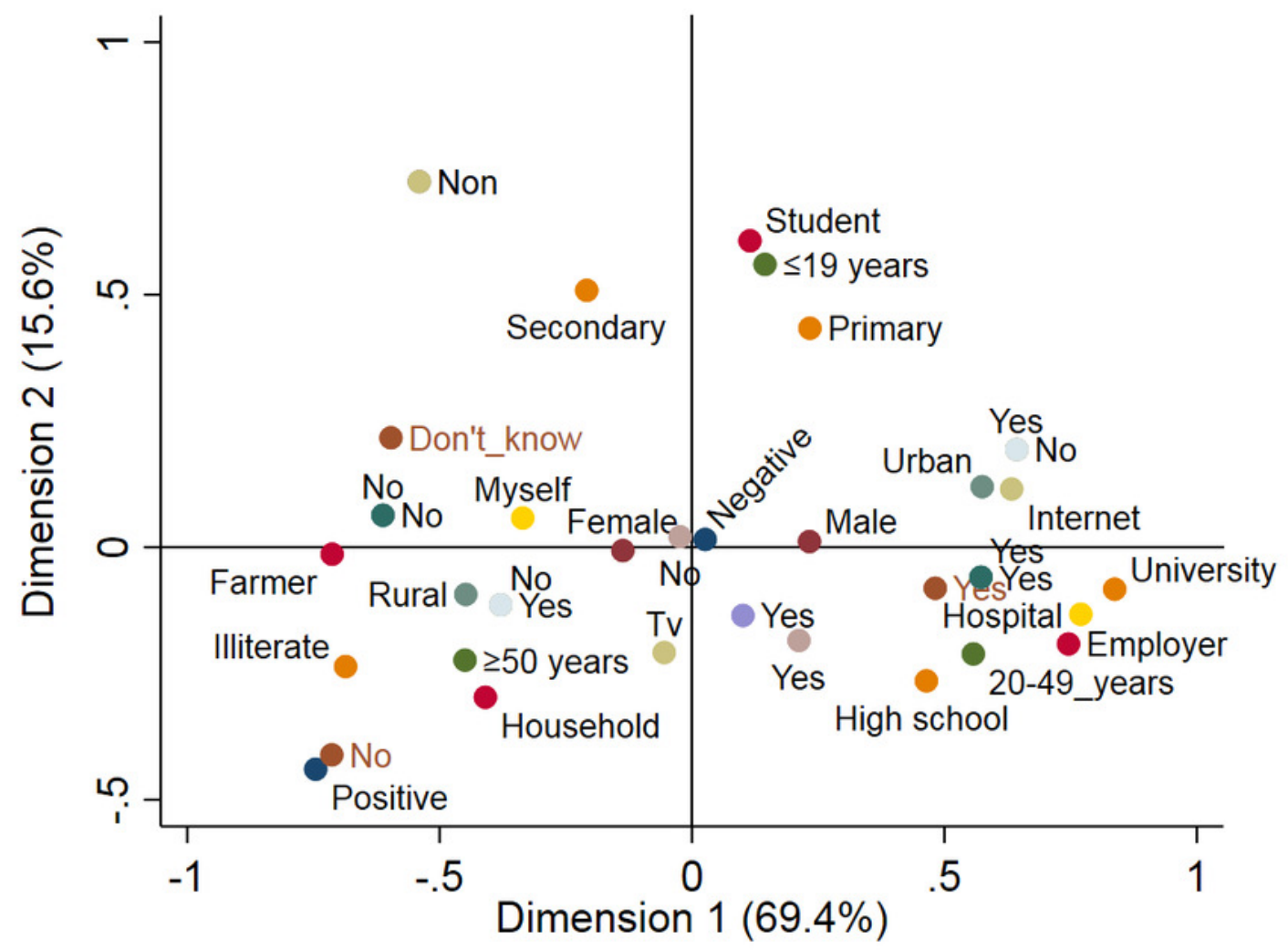

\begin{tabular}{|c|c|c|c|c|}
\hline Cases & - Gender & - Age & Education & - Residence \\
\hline - Occupation & Info. AIV & Info. source & - AIV infectious & - AIV transmission \\
\hline AIV signs & - Poultry contact & Preventive & Health care & Vaccination \\
\hline
\end{tabular}

